\title{
QTL Mapping in Crop Improvement: A Basic Concept
}

\author{
Khushboo Chandra* and Anil Pandey \\ Department of Plant Breeding and Genetics, Dr. Rajendra Prasad Central \\ Agricultural University Pusa, Samastipur, India \\ *Corresponding author
}

\begin{tabular}{|c|c|}
\hline & $A B S T R A C T$ \\
\hline & $\begin{array}{l}\text { The narrow genetic base of modern crop cultivars is a serious obstacle to sustain and } \\
\text { improve crop productivity due to rapidly occurring vulnerability of genetically uniform }\end{array}$ \\
\hline Keywords & $\begin{array}{l}\text { cultivars to potentially new biotic and abiotic stresses. However, many agriculturally } \\
\text { important traits such as productivity and quality, tolerance to environmental stresses, and }\end{array}$ \\
\hline $\begin{array}{l}\text { QTL, Marker, } \\
\text { Mapping. }\end{array}$ & $\begin{array}{l}\text { some of forms of disease resistance are quantitative (also called polygenic, continuous, } \\
\text { multifactorial, or complex traits) in nature and the jargon used by molecular biologists, the }\end{array}$ \\
\hline Article Info & $\begin{array}{l}\text { utility of DNA markers in plant breeding may not be clearly understood by non-molecular } \\
\text { biologists. Recognizing the enormous potential of DNA markers in plant breeding, many }\end{array}$ \\
\hline $\begin{array}{l}\text { Accepted: } \\
07 \text { October } 2017 \\
\text { Available Online: } \\
10 \text { December } 2017\end{array}$ & $\begin{array}{l}\text { agricultural research centers and plant breeding institutes have adopted the capacity for } \\
\text { marker development and marker-assisted selection (MAS). This review provides an } \\
\text { introduction to DNA markers, QTL and the concept of polymorphism, the principles and } \\
\text { methods of QTL analysis and also different types markers may be applied in breeding } \\
\text { programs using MAS. }\end{array}$ \\
\hline
\end{tabular}

\section{Introduction}

A QTL \{Quantitative Trait Locus (Loci) \} term is coined by Gelderman (1919) and is defined as "a region of the genome or locus of gene that is associated with an effect on a quantitative trait". A quantitative trait which is controlled by several genes, all the genes having small effects, additive in nature and is affected by environment. The phenotypes of quantitative trait are typically depicted by a bell curve.

\section{Criteria to select best targeted QTL}

\section{Size of effect}

The distance between the marker and gene of interest should be negligible in order to avoid the linkage drags which mean selection of undesirable traits along with gene for specific trait.

\section{Environmental interactions}

Most of gene identified as quantitative trait is highly influenced by environments which are polygenic in nature shows cumulative behavior under varying environment.

\section{QTL epistasis}

It is mainly the effect of linked marker over the gene of interest whether its shows hypostatic (being masked) or hyperstatic 
(shows masking) behavior under influenced environment.

\section{QTL mapping, principle, requirements and objectives of QTL mapping}

QTL mapping is process of locating genes with effects on quantitative traits using molecular markers. A major breakthrough in the characterization of quantitative traits that created opportunities to select for QTLs was initiated by the development of DNA (or molecular) markers in the 1980s.

\section{Principle}

The basic Principle is the co- segregation of marker locus and QTL together. Cosegregation is due to linkage between marker and QTL.QTL analysis depends on linkage disequilibrium which is the non-random association of alleles at different loci in a given population.

\section{Requirements}

The requirements of QTL mapping are mapping population, saturated linkage map, phenotypic screening and statistical package. Ideally markers should be $<5 \mathrm{~cm}$ from a gene or QTL. Using a pair of flanking markers can greatly improve reliability but increases time and cost.

The QTL mapping strategies are choose divergent parents, Screen for marker loci polymorphism create mapping populations for generating saturated linkage map, phenotype screening and Contrast the mean of the marker attached and pair of gene of interest at every marker locus.

The main objectives of this study to offer direct mean to investigate the number of genes influencing the trait. The location of the gene that affect traits of interest, to know the effect of genes on variation of the trait. Also to carry out study on linkage between genes of interest.

DNA based marker assisted selection (MAS).

Genetic markers that are located in close proximity to genes (i.e. tightly linked) may be referred to as gene 'tags'. Markers must be polymorphic.

There are three major types of genetic markers:

Morphological (also 'classical' or 'visible') markers which themselves are phenotypic traits or characters; Biochemical markers, which include allelic variants of enzymes called isozymes; and DNA (or molecular) markers, which reveal sites of variation in DNA (Jones et al., 1997; Winter and Kahl, 1995).

\section{Factors Affecting QTL Mapping}

Number of genes controlling the target traits and their position

Position of gene on chromosome affects the success of QTL mapping. If genes will remain close to concerned genetic marker, there will be more chance of detection of target traits or target genes.

It is based on banding pattern of markers used. If genes will remain away from concerned genetic marker, there will be more chance of crossing over.

It affect banding pattern of markers used. In this condition, it will be difficult to determine position of target genes.

Heteritability of the genes segregating in a mapping population

Generally characters governed by oligogenes or single genes are having high heteritability than governed by polygene. 
Type of mapping population used in QTL mapping

Non-random mating population is required for QTL mapping. It is result of mutation, natural selection, random drift etc.

Size of mapping population used in QTL mapping

In large sample size, QTL with small effects cannot be observed but QTL with large effects can be observed.

In small sample size also, QTL with small effects cannot be observed but QTL with major effects can be observed.

Type and number of markers in linkage maps

If there is more number of markers used, amount of precision of estimation of both QTL position and effect will be more. Here, co-dominant marker shows three types of genetic difference while dominant marker shows two types of genetic difference. So, codominant marker provides more information than dominant marker regarding recombination with in marker intervals.

\section{Phenotyping of mapping population and sample size}

The target quantitative traits are measured as precisely as possible and limited amounts of missing data can be tolerated. The power to resolve the QTL location is confined first by sample size and then by genetic marker coverage of the genome. Generally, the number of individuals in a sample might appear to be large but missing data or skewed allele frequencies in the population cause the effective sample size to diminish, thus sacrificing the statistical power.
It is must to sacrifice population size in favour of data quality and this means that only major QTL (with relatively large effect) can be detected. QTL It is also preferred to measure the target trait(s) in experiments conducted in multiple (and appropriate) locations to have a better understanding of the QTL x environment interaction,

\section{Mapping populations used in QTL mapping}

Various types of mapping population may be produced from the heterozygous $F_{1}$ hybrids:

\section{Double Haploid Lines (DHLs)}

Plants are regenerated from pollen (which is haploid) of the $F_{1}$ plants and treated to restore diploid condition in which every locus is homozygous.

Since the pollen population has been generated by meiosis, the DHLs represent a direct sample of the segregating gametes.

\section{Backcross (BC) population}

The $F_{1}$ plants are backcrossed to one of the parents.

$F_{2}$ population

F1 plants are selfed.

$\mathbf{F}_{2: 3} / \mathbf{F}_{2: 4}$ lines

$\mathrm{F}_{3 / 4}$ plants tracing back to the same $\mathrm{F}_{2}$ plant, also called $\mathrm{F}_{2}$ families.

\section{Recombinant inbred lines (RILs)}

Inbred generation derived by selfing individual $F_{2}$ plants and further single seed descent. A population of RILs represents an 'immortal' or permanent mapping population. 
Difference between conventional and marker assisted backcrossing

Figure 1 shows that identification of gene of interest in case of conventional backcrossing takes longer time up to 20 years for accumulation of desirable gene but in marker assisted backcrossing up to second generation with the help of foreground and background selection for gene pyramiding of favorable gene.

Methods for QTL mapping (Li and Wang, 2007)

\section{Single marker approach (SMA)}

It is also called as Single factor analysis of variance or single point analysis. It is widely used method for quick scanning of whole genome to determine best QTLs.

It is used for each marker locus which is free from other loci. This technique is unable to determine QTL position.

\section{Some major limitations of this approach}

The method cannot determine whether the markers are associated with one or more QTLs.

Chance of QTL detection decreases with distance between marker and QTL.

An effect of QTL is underestimated of confounding with recombination frequencies.

Its accuracy is less compare to other methods.

\section{Simple interval mapping (SIM)}

SIM was first proposed by Lander and Botstein (1989) based on linkage map and also called as two marker approach. QTL is determined in interval generated between two markers at various points. It gives more accurate results compare to single marker approach but less than CIM and MIM technique. In this technique, likelihood ratio test is used to determine every QTL position in interval created by both markers. SIM is mostly preferred as it can be easily performed through statistical packages such as MAPMAKER (Lander et al., 1987) and JOIN MAP (Stam, 1993).

Lander and Botstein (1989) developed formulae for significance levels appropriate for interval mapping when the genome size, number of chromosomes, number of marker intervals, and the overall false positive rate desired are given.

\section{Composite interval mapping (CIM)}

CIM techniques are developed by Zeng, 1994.It is used to minimize effects of various linked QTLs. It is based on one QTL and other markers used as covariates. This technique gives more precise results and used to exclude bias due to another QTLs (nontarget QTLs) linked to target QTL. It used to fit the parameters for a single QTL in one interval. The partial regression coefficient is used to determine genetic variance due to non-target QTLs.

The merits of CIM are as follows:

Mapping of multiple QTLs can be carried out by the search in one dimension.

By using linked markers as covariates, the test is not affected by QTL out of region, thereby increasing the precision of QTL mapping and by eliminating as much as the genetic variance produced by other QTL, the residual variance is reduced, thereby the efficiency of determination of QTL is increased. 


\section{Requirements}

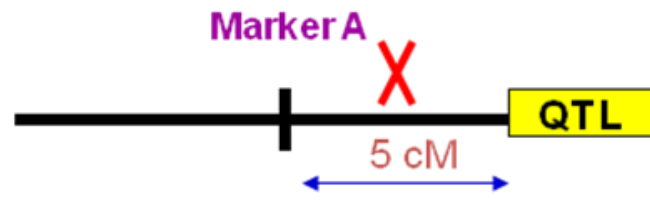

Marker A

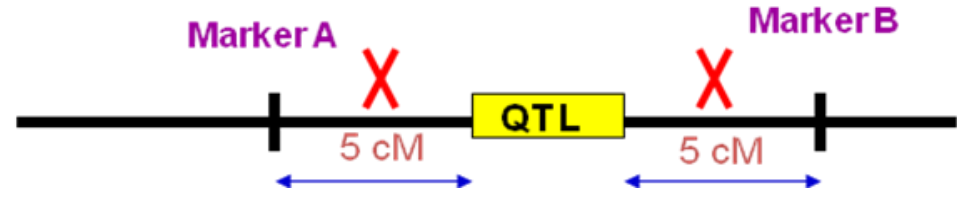

RELIABILITY FOR SELECTION

Using marker A only:

$$
1-\mathrm{r}_{\mathrm{A}}=\sim 95 \%
$$

Using markers $\mathrm{A}$ and $\mathrm{B}$ :

$1-2 \mathrm{r}_{\mathrm{A}} \mathrm{r}_{\mathrm{B}}=\sim 99.5 \%$

Fig.1 Difference between conventional and marker assisted backcrossing
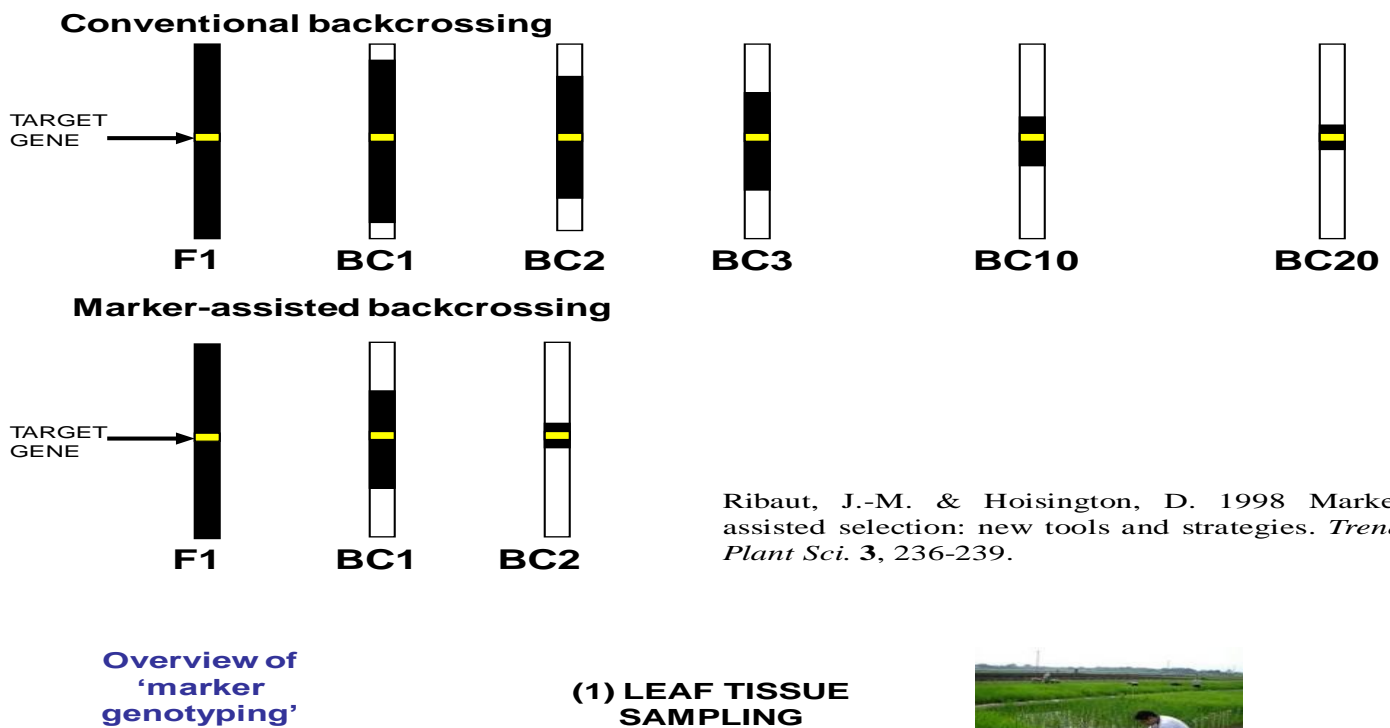

(1) LEAF TISSUE SAMPLING<smiles>C1=CC=C1</smiles>

(2) DNA EXTRACTION<smiles>[CH]1C=CC=C1</smiles>

(3) PCR

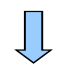

(4) GEL ELECTROPHORESIS<smiles>C1=CC=C1</smiles>

(5) MARKER ANALYSIS

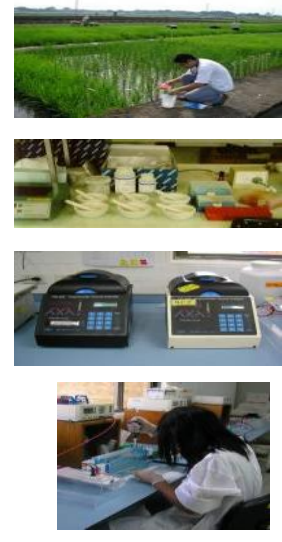

Ribaut J.-M \& Hoisington, D. 1998 Markerassisted selection: new tools and strategies. Trends Plant Sci. 3, 236-239.

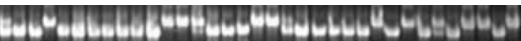




\section{Direct mean to investigate the number of genes influencing the trait}

\begin{tabular}{|c|c|c|c|c|}
\hline $\begin{array}{l}\text { Molecular } \\
\text { marker }\end{array}$ & $\begin{array}{l}\text { Restriction } \\
\text { fragment length } \\
\text { polymorphism } \\
\text { (RFLP) }\end{array}$ & $\begin{array}{l}\text { Random amplified } \\
\text { polymorphic DNA } \\
\text { (RAPD) }\end{array}$ & $\begin{array}{l}\text { Simple sequence } \\
\text { repeats(SSRs)* } \\
\text { or 'microsatellites' }\end{array}$ & $\begin{array}{l}\text { Amplified fragment } \\
\text { length } \\
\text { polymorphism } \\
\text { (AFLP) }\end{array}$ \\
\hline $\begin{array}{l}\text { Codominant }(C) \text { or } \\
\text { Dominant (D) }\end{array}$ & Codominant & Dominant & Codominant & Dominant \\
\hline Advantages & $\begin{array}{l}\text { Robust, Reliable, } \\
\text { Transferable across, } \\
\text { populations }\end{array}$ & $\begin{array}{l}\text { Rapid, simple, } \\
\text { Inexpensive, } \\
\text { Multiple } \\
\text { loci from a single } \\
\text { primer possible, less } \\
\text { DNA required }\end{array}$ & $\begin{array}{l}\text { simple, Robust and } \\
\text { reliable, Transferable } \\
\text { between, populations }\end{array}$ & $\begin{array}{l}\text { Multiple loci, High } \\
\text { levels of } \\
\text { polymorphism } \\
\text { produced }\end{array}$ \\
\hline Disadvantages & $\begin{array}{l}\text { Time-consuming, } \\
\text { laborious, expensive, } \\
\text { more DNA required, } \\
\text { Less polymorphism, }\end{array}$ & $\begin{array}{l}\text { Generally not } \\
\text { transferable, Less } \\
\text { reproducibility }\end{array}$ & $\begin{array}{l}\text { Time-consuming, } \\
\text { laborious, Usually } \\
\text { require } \\
\text { polyacrylamide } \\
\text { electrophoresis }\end{array}$ & $\begin{array}{l}\text { Complicated } \\
\text { methodology, Large } \\
\text { DNA required }\end{array}$ \\
\hline References & $\begin{array}{l}\text { Beckmann and Soller } \\
\text { (1986), Kochert } \\
\text { (1994), } \\
\text { Tanksley et al. } \\
\text { (1989) }\end{array}$ & $\begin{array}{l}\text { Penner (1996), Welsh } \\
\text { and McClelland } \\
\text { (1990), } \\
\text { Williams et al. } \\
\text { (1990) }\end{array}$ & $\begin{array}{l}\text { McCouch et al. } \\
\text { (1997), } \\
\text { Powell et al. (1996), } \\
\text { Taramino and Tingey } \\
\text { (1996) }\end{array}$ & Vos et al. (1995) \\
\hline
\end{tabular}

Collard B.C.Y., Jahufer M.Z.Z., Brouwer J.B. and Pang E.C.K., An introduction to markers, quantitative trait loci (QTL) mapping and marker-assisted selection for crop improvement: The basic concepts, Euphytica 142, 169-196 (2005)

\section{Software for QTL Mapping}

\begin{tabular}{|c|c|c|}
\hline SOFTWARE & FEATURES & REFERENCES \\
\hline MAPMAKER & Interval mapping (IM) & Lincoln et al,1992 \\
\hline MAP MANAGER & $\begin{array}{l}\text { QTXSMA, SIM, CIM, searches for interacting QTLs, } \\
\text { etc. }\end{array}$ & Manly and elliott, 1991 \\
\hline QGENE & $\begin{array}{l}\text { Single Marker Analysis (SMA), IM and multiple-trait } \\
\text { analysis }\end{array}$ & Nelson, 1997 \\
\hline MAPQTL & $\begin{array}{l}\text { IM, Composite Interval Mapping (CIM), non-parametric } \\
\text { mapping with the kruskal-Wallis rank sum test per } \\
\text { marker (for non-normally distributed data), permutation } \\
\text { tests, etc. }\end{array}$ & Van and Mallipard,1996 \\
\hline PLABQTL & $\begin{array}{l}\text { Simple Interval Mapping (SIM), CIM, also analysis for } \\
\text { QTL x Environment (QE) interactions }\end{array}$ & Utz and Melchinger, 1996 \\
\hline MQTL & $\begin{array}{l}\text { SIM, CIM, also analysis for main effect, QE interactions, } \\
\text { and can perform permutation tests }\end{array}$ & Tinker and Mather, 1995 \\
\hline $\begin{array}{l}\text { QTL } \\
\text { CARTOGRAPHE } \\
\text { R }\end{array}$ & $\begin{array}{l}\text { SMA, SIM, CIM, Bayesian Interval Mapping (BIM), } \\
\text { Multiple Interval Mapping (MIM), multiple trait } \\
\text { analysis, permutation tests, etc }\end{array}$ & Basten et al,1994 \\
\hline MULTIMAPPER & $\begin{array}{l}\text { Mapping QTL with epistatic effects, QE interaction } \\
\text { effects etc. }\end{array}$ & Sillanpaa, 1998 \\
\hline
\end{tabular}


CIM is more efficient than SIM, but not widely used in QTL mapping as in SIM.

\section{Multiple intervals mapping (MIM)}

It is recent method of QTL Mapping.MIM techniques are developed by Jansen and Stam (1994). Multiple Interval Mapping (MIM) is the extension of interval mapping to multiple QTLs, just as multiple regression extends analysis of variance. It is used to map multiple QTLs. This method is potential tool for detection of QTL X QTL interaction.

\section{Inclusive composite interval mapping (ICIM)}

An approach to QTL (quantitative trait locus) mapping for populations derived from biparental crosses. QTL mapping is based on genetic linkage map and phenotypic data.

To locate individual genetic factors on chromosomes and to estimate their genetic effects.

ICIM has been successfully used in Wild and cultivated soybeans in mapping conserved salt tolerance QTL

Rice mapping tiller angle QTL and grain length QTL

Wheat mapping flour and noodle, color components and yellow pigment content and adult-plant resistance to stripe rust QTL.

ICIM extended to map Maize Nested Association Mapping design recently proposed by the Buckler laboratory at Cornell University.

\section{Statistical method for QTL mapping}

T-test is used for determination of significant differences between various genotypes groups or marker classes. Linear regression Analysis is used for determination of position as well as effect at QTL

Multiple regression Analysis is used for determination of additive as well as dominance effect at QTL simultaneously.

Two commonly used mapping functions that convert recombination frequency into centimorgan $(\mathrm{cM})$ distance are

Kosambi mapping function, which assumes that recombination events influence the occurrence of adjacent recombination events, and

Haldane mapping function, which assumes no interference between crossover events.

Linkage between markers is usually calculated with an odds ratio (i.e., the ratio of linkage versus no linkage). This ratio is more conveniently expressed as the logarithm of the ratio and is called a logarithm of odds (LOD) value or LOD score (Risch, 1992). LOD values of $>3$ are typically used to construct linkage maps. $\mathrm{L}$

OD values may be lowered in order to detect linkage over a greater distance. (Collard et al., 2005)

Probability of the data occurring with a QTL Log of odds (LOD score) $=$

Probability of the data occurring with no QTL

Positive LOD scores favor the presence of linkage, whereas negative LOD scores indicate that linkage is less likely

\section{Application of QTL Mapping}

MAS, MABC and MARS results in indirect selection of QTLs which requires less time, labour, resource and space. 
Germplasm screening of diversified materials for biotic and abiotic stresses can done in early stage like seedling stage.

No need of pathogen inoculation and disease development in case of disease resistance trait. Reduction in Negative selection means linkage drag during introgression of QTL

The genetic integration of agronomical, physiological and gene expression related traits (the scientific value of QTL analysis)

Recently at IARI, New Delhi validation of QTLs for maize conferring downy mildew resistance (George et al.,2003;Nair et al.,2005)

\section{Limitation of QTL Mapping}

High cost

Require sophistication and technical expertise

\section{References}

Collard B.C.Y., Jahufer M.Z.Z., Brouwer J.B. and Pang E.C.K., (2005). An introduction to markers, quantitative trait loci (QTL) mapping and markerassisted selection for crop improvement: The basic concepts, Euphytica 142, 169-196

Li, H., G. Ye and J. Wang (2007). "A Modified Algorithm for the Improvement of Composite Interval Mapping". Genetics. 175(1): 361-374.

Ribaut, J.-M. \& Hoisington, D. 1998 Markerassisted selection: new tools and strategies. Trends Plant Sci. 3, 236-239.

Shaukeen Khan (2015). QTL Mapping: A Tool for Improvement in Crop plants. Research Journal of Recent Sciences 4(IVC-2015), 7-12.

\section{How to cite this article:}

Khushboo Chandra and Anil Pandey. 2017. QTL Mapping in Crop Improvement: A Basic Concept. Int.J.Curr.Microbiol.App.Sci. 6(12): 835-842. doi: https://doi.org/10.20546/ijcmas.2017.612.089 